\title{
Resenha
}

\section{A democracia republicana de Philip Pettit}

\author{
Luís Falcão \\ Doutorando em Ciência Política pelo IESP-UERJ \\ luis.alves.falcao@gmail.com
}

\section{On the people's terms: a republican theory and model of democracy. Cambridge: Cambridge University Press. \\ Philip Pettit, 2012. 338 p.}

\begin{abstract}
Resumo: A presente resenha visa apresentar os argumentos centrais contidos na recente obra de Philip Pettit, priorizando os conceitos por ele mesmo trabalhados em outras publicações, com especial ênfase para as mais relevantes sobre o tema. Sua obra busca consolidar um enorme conjunto de ensaios produzidos por ele nos últimos anos, quase sempre focados em respostas às críticas feitas ao seu livro mais conhecido, Republicanism. Destaca-se no livro resenhado o aspecto mais institucional de sua proposição política e a dimensão democrática. Nesta, encontra-se o esforço teórico de aproximação com o republicanismo moderno, mas sem descuidar do conhecido conceito de liberdade como não dominação. Além disso, a presente resenha busca contribuir para o entendimento da posição de Pettit no diálogo contemporâneo a respeito do republicanismo e para a possível relação com a tradição contratualista. Argumenta-se que o foco do autor, ao desenvolver seu diálogo com a tradição republicana, reside nos pensadores marcadamente afeitos ao republicanismo e simultaneamente ao direito natural. Por este ângulo, Pettit se insere no atual debate sobre a democracia. Por fim, buscou-se apontar o caráter original de sua contribuição.
\end{abstract}

Palavras-chave: Philip Pettit; Republicanismo; Democracia; Contratualismo.

\footnotetext{
Abstract: This review aims to present the central arguments contained in the recent work of Philip Pettit, prioritizing the concepts he worked in other publications, with special emphasis on the most relevant of them. His work seeks to consolidate a large number of papers produced by him in recent years almost always focused on responses to criticisms of his best-known book, Republicanism. In the book reviewed more then the other there is a much more important institutional aspects of his political theory focusing on the democratic
} 
dimension of his republicanism. In the On the People's Term there is the theoretical effort approach with modern republicanism, but without neglecting the known notion of freedom as non-domination. Furthermore this review seeks to contribute to the understanding of the Pettit position in the contemporary debate about republicanism and the possible relationship with the contractarian tradition. It is argued that the focus of the author is the republican tradition but simultaneously with the natural law thinkers. For this point of view Pettit discuss with the current debate on democracy. Finally we sought to point out the originality of his contribution.

Keywords: Philip Pettit; Republicanism; Democracy; Contractarianism.

A segunda metade do século XX presenciou o ressurgimento, sob diversos aspectos e abordagens, do pensamento republicano, praticamente negligenciado desde, pelo menos, início do século XIX. Entre as proposições, ganharam destaque acadêmico perspectivas históricas, mais reconhecidamente com a chamada Escola de Cambridge. Por outro lado, a ascensão de diversas reflexões sobre a democracia, no mesmo período, produziu um arrefecimento de novas proposições teóricas republicanas. Mais marcadamente nos anos 1970, as teorias políticas normativas, em um amplo escopo residente na tradição liberal, acabaram por, ao menos em parte, reorganizar o debate público e, com isso, tencionaram o contraste com o republicanismo. Em resposta, os que se debruçam sobre esta última tradição quase sempre resistem à aceitação dos percursos e fundamentos do liberalismo, não obstante o reconhecimento de particulares proximidades. Comumente, este debate repôs antigas dicotomias, desde Bentham, Constant e Berlin, em torno do conceito de liberdade no centro do diálogo. As questões de fundo teórico postas pelo liberalismo, quase sempre eram respondidas pelos estudiosos do republicanismo sob um ponto de vista histórico ou através da revitalização de autores consagrados. Esse debate sofre uma inflexão com os escritos de Philip Pettit.

A primeira edição de Republicanism: a theory of freedom and government, publicada em 1997, de pronto causou grande impacto. Não é necessário muito esforço para perceber que, já nas primeiras páginas, a obra pretendia oferecer respostas, em forma e conteúdo, distintas daquelas que vinham sendo acusadas de historicismo ou de mera erudição arqueológica. A inovação de Pettit consiste, assim, em apresentar formulações analíticas em moldes assumidamente similares àqueles usados pelos liberais (Pettit, 1997: 11). Por outro lado, o autor também não descuida das avaliações históricas. Um dos pontos mais originais na proposição de Pettit, que será seguido no livro ora resenhado, 
é justamente produzir sínteses de tradições em torno de conceitos e, com isso, formular uma versão própria do assunto, como é o caso da liberdade.

Logo assim que o livro chegou a público, respostas positivas e negativas foram produzidas no intuito de comentar as análises propostas a respeito do percurso da filosofia política moderna ou com o objetivo de avaliar a proposição teórica então realizada. Contudo, a força do argumento de Pettit reside, e isso se confirma na obra aqui em questão, na disputa em torno do conceito que conferiu unidade à tradição liberal. Assim, o republicanismo de Pettit não é senão uma alternativa ao conceito liberal de liberdade. Centrando-se neste tema, Pettit não se dedicou com o mesmo afinco a outros pontos da tradição republicana, como o governo misto, o império da lei e a participação cívica nos negócios públicos. Objeto de crítica nos últimos anos, as respostas foram dadas paulatinamente em dezenas de ensaios que, agora, encontram-se unificadas em On the people's term.

O livro segue a argumentação posta nos fins dos anos 1990. Mas, antes de uma singela repetição, Pettit procura, agora, enfatizar aquilo que não fora objeto central de análise na obra anterior. A sistematicidade da exposição do argumento torna-o ainda mais analítico do que em Republicanism. Pettit restringe o uso dos autores clássicos e, em determinados momentos, pressupõe do leitor não apenas algum contato com esta literatura, mas também um mínimo de informações a respeito das teorias do próprio Pettit.

Assumindo a interpretação ítalo-atlântica do republicanismo da obra de Pocock (Pettit, 2012: 8), Pettit permite uma interpretação de sua predileção por um determinado conjunto de autores que não necessariamente são os mesmos dos de Pocock. É clara a opção do autor de The Machiavellian Moment pelos pensadores afeitos ao realismo maquiaveliano, preterindo, desse modo, aqueles que se fundam em argumentações jusnaturalistas e contratualistas. De fato, autores com o John Milton, Algernon Sidney, Richard Price e Joseph Priestley, claramente devedores do direito natural e igualmente republicanos, pouco espaço ocupam na volumosa obra de 1975.'Não seria isso significativo caso Pettit não se apoiasse tanto na tradição ítalo-atlântica e, simultaneamente, nesses pensadores. O fato é que Pettit identifica nos jusnaturalistas republicanos o fundamento principal, do ponto de vista histórico, do conceito de liberdade republicana

1 Do lado oposto, Pocock prioriza pensadores como Maquiavel, Guicciardini, Contarini, Harrington, Montesquieu, Hume, Madison e Hamilton, todos distantes do direito natural. 
como não dominação, mesmo que nem sempre expresse isso. Sabendo igualmente que o direito natural moderno ofereceu, segundo o próprio Pettit, o escopo, de Hobbes a Rawls (Pettit, 2012: 144), do liberalismo e que este é a definição de liberdade como não interferência, a dimensão negativa da liberdade como não dominação já não pode mais ser escondida. Na verdade, o próprio Pettit já havia admitido isso (2002: 340). Da unidade do direito natural, republicano e liberal, o autor extrai sua teoria da liberdade, retomada no primeiro capítulo.

O segundo capítulo do livro, Social Justice, trata das derivações relacionadas às questões de legitimidade e justiça. Chama a atenção o fato de Pettit abordar o tema da justiça como um critério, sob a perspectiva da liberdade como não dominação, intrinsecamente republicano. A justificativa se assenta não em uma teoria da justiça que se sustentaria por si mesma, como é mais comumente encontrada nos escritos contemporâneos, mas dependente, tanto quanto o próprio critério da legitimidade, das relações de não dominação. A respeito da justiça, constrói-se uma teoria que se debruça sobre como obliterar dominações entre cidadãos e, no caso da legitimidade, a preocupação incide na relação entre cidadão e Estado. Não parece estranho, nessa altura da argumentação (Pettit, 2012: 77-81), que as citações comportem positivamente, embora também limitadamente, obras consagradas de Sen, Rawls e até mesmo Nozick e Locke² (Pettit, 2012: 93). Possivelmente, encontra-se aqui um esforço conciliatório.

O uso desses autores poderia ser entendido como uma inserção do tema da justiça na tradição republicana identificada por Pocock, que, definitivamente, não prioriza o tema. Nesse sentido, uma leitura apressada do texto de Pettit poderia colocá-lo em uma situação contraditória. Mas os artifícios argumentativos de Pettit configuram uma dimensão normativamente igualitária como uma das atribuições centrais do Estado republicano. Após uma discussão de diferentes perspectivas e uma breve digressão metodológica, seus objetivos se clareiam a partir de três pontos: pessoas livres assim o são pela segurança em realizar suas escolhas específicas, são livres na medida em que o exercício dessas escolhas seja garantido e, por fim, que as garantias dos dois princípios

2 A proximidade de Pettit com Skinner (2002), não obstante as diferenças (Pettit, 2002), quase sempre é proporcionada pelo tema da liberdade. Entretanto, cabe destacar o conhecido artigo de Skinner cujo argumento central é, mobilizando Maquiavel e Harrington, mostrar que a distinção entre o governo de jure (das leis) e o de facto (dos homens) ainda persiste na contemporaneidade no liberalismo de Rawls e Nozick. Pettit, por seu lado, utiliza justamente o império da lei como justiça republicana, o que Skinner insiste que não há em Rawls. Com contornos distintos, Skinner aceita, de modo bem particular, a tese da liberdade negativa em autores republicanos (1998). 
anteriores sejam cumpridas. O terceiro ponto é aquele que identifica o caráter específico do republicanismo, sobretudo, perante os moldes liberais de justiça. Contudo, o arcabouço dessa teoria repousa fundamentalmente sobre a não dominação. O argumento se sustenta no fato de que o liberalismo advoga pelo cumprimento das escolhas individuais e da garantia do exercício dessas escolhas. Porém, não o faz de modo simultâneo e complementar. Para Pettit, os dois princípios devem ser coadunados de modo que se projete um horizonte a ser alcançado. Nesse sentido, o aprofundamento da igualdade assume uma dimensão teleológica ou consequencialista, mas não transcendente (Pettit, 2012: 124), em direção à justiça. ${ }^{3}$

A identificação dessa igualdade pressupõe um atributo assumidamente ciceroniano (Pettit, 2012: 88): a igualdade de liberdade. Ao sustentáculo do terceiro ponto (cumprimento das escolhas e de seus exercícios) é necessária a provisão estatal de recursos e proteções iguais. Estes dois argumentos devem estar constantemente submetidos ao "teste de globo ocular", isto é, que qualquer pessoa possa olhar nos olhos de qualquer outra pessoa sem receio ou humilhação. O critério deste teste acompanha Pettit por toda a obra. Quanto à relação com a justiça, deve-se submetê-la a tal teste na medida em que os recursos e proteções sejam iguais, mesmo que para isso sejam necessários tratamentos diferentes para casos específicos (Pettit, 2012: 91). Todavia, de modo que o critério do teste não produza mais diferenças, uma vez que é plausível supor uma situação que pretenda corrigir disparidades, mas produza outras, dois critérios são ainda necessários. O primeiro deles é a garantia de que o exercício da liberdade individual não oblitere ou limite a coletiva. O segundo é que a satisfação individual com as escolhas feitas não possa limitar ou ser limitada pela coletiva.

A partir de então, a teoria da justiça ganha contornos mais nítidos, sempre em direção à defesa da não dominação. Uma vez que qualquer lei é, por definição, um ato de

3 Em alguns pontos da exposição, Pettit sugere que as liberdades básicas, contrastadas com os constrangimentos impostos, figuram uma determinada forma de metafísica ou lógica (2012: 95), o que pode apontar para uma diferenciação entre metafísica e transcendência na perspectiva do autor. Assim, a teleologia ou o consequecialismo apontam para a garantia de um aprofundamento contínuo da igualdade de liberdade. Parece fazer sentido que esta metafísica ou lógica sejam o instrumento capaz de produzir um marcador central das liberdades básicas. Duas são as linhas de argumentação, que se desenvolvem paralelamente: a definição das liberdades básicas, pela metafísica ou lógica, e o aprofundamento da igualdade dessas mesmas liberdades, apreendidos por parâmetros teleológicos ou consequencialistas. Em outro texto (2006: 36), já havia sido identificado pelo autor que o consequecialismo não era mais do que uma determinada forma teórica do contrato social. Sabe-se que a tradição contratualista concedeu destaque, desde os primeiros séculos da modernidade, às teorias da justiça. Nesse sentido, Pettit concede, à teoria do contrato, sua dimensão consequencialista da justiça e exclui qualquer critério transcendente. 
constrangimento, cabe, pois, identificar de que se trata as liberdades básicas, de modo que a lei não as fira. Nesse sentido, é plausível que se restrinja a preocupação com a liberdade apenas ao espaço em que ela é possível de ser realizada. Por isso, a justiça republicana não deve atentar para as habilidades específicas de determinados indivíduos, mas sim para aquelas generalizáveis. Por isso também, pode-se resumir, a função estatal deve se vincular às escolhas que podem ser exercidas e satisfeitas simultaneamente por todos os cidadãos. O autor retoma a relação com Rawls e, apesar de admitir que sua teoria é o que se espera da justiça, marca a diferença para com o autor de $A$ theory of justice com o republicanismo pelo fato de que esta tradição necessita dos recursos para as liberdades básicas e aquele não requer a proteção contra a dominação. " "This makes clear that for Rawls domination is not a problem as such" (Pettit, 2012: 108).

Do ponto de vista programático, a teoria republicana da justiça necessita de uma estrutura capaz de oferecer educação e ambientes, institucionais e materiais, com um alto nível de igualdade (Petti, 2012: 110-111), independentemente do status individual ou dos motivos causadores de disparidades. É preciso destacar que Pettit deixa claro que a igualdade de que fala não se refere a uma igualdade substancial, por exemplo, do ponto de vista econômico ou social. Todavia, na plausível situação em que a não dominação esteja ameaçada, sob a forma de desigualdades sociais e econômicas, cabe, pois, a intervenção estatal. Desse modo, sob determinadas circunstâncias, é necessária a intervenção estatal para impedir a dominação, porém isso não é suficiente. Do lado oposto, é suficiente a boa vontade ou filantropia dos cidadãos, mas não pode ser tida como necessária (Petti, 2012: 113).

Buscando diferenciar os termos da justiça com os da legitimidade, Pettit, por um lado, insere a ideia rousseauiniana da vontade geral como expressão dos anseios de todos para com a posição do Estado, por outro, atem-se igualmente na definição negativa de liberdade, isto é, aquilo que se constitui em oposição ao despotismo e ao poder externo (Pettit, 2012: 130). Os dois pontos carregam consigo uma clara dívida para com a tradição jusnaturalista, seja pela referência explícita a Rousseau, seja pela implícita a Locke, ou na discussão de seu apogeu teórico que ainda inclui Hobbes (Pettit, 2012:

4 Em resenha publicada em 1974, Pettit apresenta uma avaliação de A theory of justice diversa desta, embora compatível. Destaca a dimensão democrática de Rawls, bem como o contrato social. Porém, o aspecto central reside na crítica sobre a incapacidade desta teoria da justiça produzir critérios universais. A crítica ora sob destaque, o problema da dominação, não mereceu o mesmo reconhecimento quatro décadas atrás. 
141-142). Apesar da dívida histórica, Pettit reconhece que, em geral, as teorias recentes do contratualismo e utilitarismo tendem a negligenciar o tema da legitimidade, o que colocaria a teoria republicana mais próxima da tradição democrática. Como já havia anunciado anteriormente, o autor segue de perto, diferentemente do que faz com a teoria da justiça, a relação entre Estado e sociedade. "Given that a state is necessary for justice, there is an issue about how it ought to relate to its citizens, as distinct from the issue of how the citizens ought to relate to one another. And that, as I conceive of it, is the issue of legitimacy" (Pettit, 2012: 136). Nesse sentido, justiça e legitimidade são conceitos separados que se complementam em prol da liberdade.

Rejeitando correntes definições de legitimidade, Pettit parte para o que considera o uso republicano do conceito, a partir do problema de como conciliar a submissão política, imposta pela necessária coerção estatal, com a liberdade pessoal. Nesse ponto, o argumento se fecha e se mostra coerente, pois apenas a liberdade como não dominação é capaz de recepcionar legitimamente coerções estatais, vinculadas a um regime legal, sustentadas no controle popular (Pettit, 2012: 149). Justifica-se, assim, a proximidade com a tradição democrática, uma vez que a legitimidade republicana se vincula à capacidade de o povo controlar as ações estatais. Por isso, emerge a necessidade de diferenciar controle de consentimento: o primeiro termo afirma uma perene participação nas decisões públicas e o segundo uma aceitação feita no passado que não pode ser alterada (Pettit, 2012: 158).

O passo seguinte é destrinchar quais são os limites do controle. Para isso, trata das condições políticas dadas do mesmo modo que se faz com as leis da física (Pettit, 2012: 161), uma vez que existem opções que não podem ser escolhidas, como a existência ou não de Estados, a vida sob seu domínio e a escolha do país para se viver. Assim, o artifício argumentativo do estado de natureza, que negligencia as imposições contingenciais, utilizado pelos contratualistas não se apresenta adequado por causa de necessidades históricas e políticas (Pettit, 2012: 163). Esse ponto é especialmente importante, pois tradicionalmente o tema da legitimidade é mais desenvolvido por pensadores do contrato social, apesar do autor afirmar que contemporaneamente o assunto foi abandonado. Mesmo que Pettit se recuse a utilizar o artifício do estado de natureza, não nega sua plausibilidade argumentativa como ponto de partida da reflexão. Todavia, não obstante as necessidades históricas, o controle popular pode ser lido a partir da 
dimensão igualitária com a qual os Estados devem tratar os cidadãos, de modo que não sejam submetidos a vontades alheias. Para isso, é preciso que todos os cidadãos tenham a mesma influência no controle estatal (Pettit, 2012: 179), fundamento democrático.

Dois são os termos que tipificam a democracia: a influência e o controle. Tratados nos dois últimos capítulos como dois lados de uma mesma versão democrática, os temas se entremeiam de modo a incorporarem-se um ao outro sob a perspectiva estatal e popular. O primeiro ponto de sua democracia é aquele originário da Grécia antiga: a assembleia. Comentando os autores que se opõem à ideia de governo misto - Bodin, Hobbes e Rousseau -, o autor une à assembleia a tradicional noção de mistura de poderes e contraposição de funções como um critério válido para a democracia republicana. Assim, diante dessas duas doutrinas, impõe-se a necessidade de um esquema de representação responsiva, de modo que os eleitos sejam constantemente avaliados pelos eleitores (Pettit, 2012: 198). Por isso, recai-se sobre a noção de que apenas uma representação que seja o reflexo das demandas da sociedade é capaz de sustentar a liberdade como não dominação. De fato, como o próprio Pettit reconhece (Pettit, 2012: 207), o sistema eleitoral adotado é apenas a parte menos importante desse tipo de representação que a democracia republicana exige. A contraparte do imperativo de uma profunda perspectiva igualitária do controle governamental se faz justamente com a dimensão individual do modelo. Ora, se a importância da igualdade é que todos possam desfrutar dela, cabe ao resultado dos esforços individuais garantir o mesmo nível de influência. Novamente, Pettit adentra no diálogo com os liberais na importância que sua teoria confere aos indivíduos. O autor admite as diferenças de capacidades e habilidades individuais como um ponto relevante para a política, tanto que precisam ser preservadas, mas elas não podem provocar uma discrepância nas influências individuais. "What is required, as we saw, is a system of collective control in which individuals equally share" (Pettit, 2012: 209). Desse modo, mesmo que o critério da maioria seja aceitável, é, antes, necessário que os direitos individuais sejam garantidos (Pettit, 2012: 217).

Parece claro, nessa altura da exposição, que o império da lei, um dos critérios distintivos do republicanismo (Pettit, 2012: 118), se encontra acolhido pela tensão entre igualdade e direitos individuais de um lado, e governo misto, de outro. Insere ainda a esse espectro a dimensão participativa da cidadania contestatória em chave alternativa àquela tradicional versão ciceroniana da virtude. Para tal, a espontânea e interessada 
participação cívica nos negócios públicos (Pettit, 2012: 228), tema este igualmente importante para o controle democrático, é peça-chave. Observando o texto a uma distância maior, percebe-se que a inicial rejeição a proximidades com formulações utópicas de participação popular produziu a aceitação, por hipótese, de formulações liberais do comportamento humano e tomou o interesse individual como ferramenta propulsora da participação e, com ela, da cidadania. De uma ponta a outra do discurso, a cidadania constitui o cerne dos problemas e das soluções da influência democrática.

O controle democrático se funda naquilo que Pettit chamou de ontologia política (Pettit, 2012: 240). Partindo de uma crítica ao modelo democrático inaugurado por Schumpeter, Pettit reitera a necessidade de que a influência sem controle não passa de um modo de legitimação do poder em moldes aquém daqueles definidos pela tradição republicana. Nesse sentido, mais uma vez, a perspectiva do que Pettit identifica como a tradição liberal de democracia se apresenta como uma ferramenta necessária, mas não suficiente. A classificação que o autor opõe à democracia schumpeteriana é a vontade geral de Rousseau, capaz de inserir a condição suficiente da democracia.

Depois de uma definição própria de interesse público, pós ao invés de pré-social e não corporativo, uma vez que se realiza na confluência igualitária da diversidade, apresenta seu argumento. "The public interest, conceived in this way, is composed of those goods that anyone who accepts the necessity of living on equal terms with others is likely to want to have collectively guaranteed or promoted" (Pettit, 2012: 245). Mais uma vez, o autor se esforça para não receber qualquer crítica que lhe possa caracterizar como utopista, romântico ou ingênuo. Desse modo, ao inserir a virtude como elemento operador do interesse público, a partir das palavras de Richard Price (Pettit, 2012: 247), deve-se sempre ter em mente a necessidade do controle popular e é justamente nesse sentido que o controle se expressa em termos republicanos. Aliado a este bloqueio às possíveis críticas, Pettit insere o utilitarismo e a conhecida metáfora da mão invisível como modos de expressão das tensões e divergências populares capazes de produzir algum nível de estabilidade e uniformidade do controle do povo perante o governo. Em suma, a atração necessária para que se exerça o controle governamental deve

5 O exemplo utilizado pelo autor é da liberdade religiosa. A diversidade de crenças religiosas não limita ou impede a convivência delas. Pelo contrário, é da percepção de que todas as crenças devem ser igualmente livres para se expressarem que emerge o interesse público. Em outros termos, o interesse público pode ser lido como a interseção dos interesses privados apenas na medida em que sustentam a igualdade. 
atender a duas condições: interesse público e mecanismo da mão invisível. O primeiro, relacionado a um esquema igualitário e coletivo, o segundo, liberal e individual. Em outros termos, a realização do controle democrático faz-se sob insígnias daquilo que é conhecido como o republicanismo clássico, sustentado, sobretudo, na virtude e nas instituições e nos interesses segmentários, tema claramente recepcionado a partir da tradição liberal, relacionado à mão invisível e ao utilitarismo (Pettit, 2012: 276).

A compatibilidade desses dois modos de reflexão, tão esgarçados nas últimas décadas, foi possível não apenas pela originalidade da leitura de Pettit de autores reconhecidamente republicanos e afeitos ao direito natural, mas também por sua perspicácia na caracterização das tradições do pensamento político. O autor, então, preocupa-se com a produção de normas gerais que tipificam concordâncias quanto ao conteúdo de cada política governamental envolvida (Pettit, 2012: 266). Nesse sentido, o que Pettit define como regulação deliberativa reintroduz um tema tradicionalmente tratado pelos republicanos não adeptos das teorias do direito natural: o conflito e o dissenso. "The difference of perspective and practice between the two approaches shows up in the fact that whereas dissensus always represents a second-best for deliberative democrats, it is entirely acceptable, even desirable, within the present approach" (Pettit, 2012: 268). Assim, por um caminho quase surpreendente, o autor retoma os aspectos centrais da tradição ítalo-atlântica (Pettit, 2012: 278). A ontologia política de que fala Pettit realiza-se no aspecto dual de um modelo de democracia republicana, institucionalmente, coadunando a ideia de uma assembleia de representantes (utilitarismo e mão invisível) com uma assembleia representativa (interesse público). Mesmo que os detalhes de tal união não sejam debatidos, a proposta ganha forma na medida em que se assenta em um "demos" possuidor de "kratos" (Pettit, 2012: 287).

A interseção firmada por Pettit no diálogo com os autores - republicanos e jusnaturalistas - representa bem os termos postos pela obra. Se, por um lado, o autor não esconde as dívidas intelectuais com o liberalismo, como não é estranho em seus ensaios, por outro, não deixa à margem os pontos centrais do republicanismo. Porém, cabe ressaltar, mesmo que Pettit reivindique que o diálogo se faz com a identidade apresentada por Pocock (2003), não são os autores em destaque em The machiavellian moment que constituem o cerne dos argumentos de On the people's term. Antes de uma fraqueza, tal opção, por vezes implícita no texto, mostra-se uma força na medida não apenas em 
que desfruta de originalidade, mas, sobretudo, quando chama para si a responsabilidade sobre a formulação teórica. Se a notoriedade de Pettit foi devida a Republicanism (1997) e sua teoria da liberdade republicana, On the people's term não deixa nada a desejar aos aspectos mais importantes das teorias contemporâneas da democracia.

\section{Referências bibliográficas}

PETTIT, Philip. 1974. A theory of justice. Theory and Decision, 4(1): 311-324.

2006. Can contract theory ground morality? In: DREIER, J (ed.). Contemporary debates in Moral Theory. Oxford: Blackwel Publisher, p. 77-96.

2002. Keeping republican freedom simple: on a difference with Quentin Skinner. Political Theory, 20(1): 338-356.

2012. On the people's term: a republican theory and model of democracy. Cambridge:

Cambridge University Press.

. 1997. Republicanism: a theory of freedom and government. Oxford: Oxford University Press.

POCOCK, J. A. G. 2003. The machiavellian moment: florentine political thought and the atlantic republican tradition. $2^{\underline{a}}$ edition. Princeton: Princeton University Press.

SKINNER, Quentin. 2002. A third concept of liberty. Proceedings of the British Academy, 117(1): 237-268

1998. Liberty before liberalism. Cambridge: Cambridge University Press.

Recebida 13/11/2013

Aceita: 6/4/2014 